\title{
Lessons Learned from Historical Analysis of Seven Decades of Educational Scholarship at McMaster University School of Nursing
}

\author{
Janet Landeen \\ McMaster University, landeen@mcmaster.ca \\ Kathryn Fisher \\ McMaster University, fisherka@mcmcaster.ca \\ Iris Mujica \\ McMaster University, mujicai@mcmaster.ca \\ Barb Carpio \\ McMaster University, carpio@mcmaster.ca \\ Ruth Chen \\ McMaster University, chenrp@mcmaster.ca \\ Lynn Martin \\ McMaster University, mart|@mcmaster.ca \\ Olive Wahoush \\ McMaster University, wahousho@mcmaster.ca \\ Marissa Bird \\ McMaster University, birdm3@mcmaster.ca
}

Follow this and additional works at: https://qane-afı.casn.ca/journal

Part of the Nursing Commons

\section{Recommended Citation}

Landeen, Janet; Fisher, Kathryn; Mujica, Iris; Carpio, Barb; Chen, Ruth; Martin, Lynn; Wahoush, Olive; and Bird, Marissa (2020) "Lessons Learned from Historical Analysis of Seven Decades of Educational Scholarship at McMaster University School of Nursing," Quality Advancement in Nursing Education - Avancées en formation infirmière: Vol. 6: Iss. 2, Article 4.

DOI: https://doi.org/10.17483/2368-6669.1257

This Article is brought to you for free and open access by Quality Advancement in Nursing Education - Avancées en formation infirmière. It has been accepted for inclusion in Quality Advancement in Nursing Education - Avancées en formation infirmière by an authorized editor of Quality Advancement in Nursing Education - Avancées en formation infirmière. 


\section{Lessons Learned from Historical Analysis of Seven Decades of Educational Scholarship at McMaster University School of Nursing}

\section{Cover Page Footnote}

This research was supported by an educational grant of the Nursing Education Research Unit, School of Nursing, McMaster University. The team wishes to thank Jenna Bloemendal, Melissa Caza, Priscila Ip, Caralyn Kelly-Stradiotto, and Alissa Ragnanan, for their assistance on this project, as well as the many others who contributed their time and their stories. Cette recherche a été appuyée par une subvention d'étude de la Nursing Education Research Unit de l'école de sciences infirmières de la McMaster University. L'équipe souhaite remercier Jenna Bloemendal, Alissa Ragnanan et Priscila Ip pour leur aide. 


\section{Introduction}

The 70th anniversary of the School of Nursing (SON) at McMaster University was fast approaching, and the question arose: how could this milestone be honoured? Historically, the SON had been a leader, nationally and internationally, in educational innovations and perhaps there was something to be learned from the past that could lead to new approaches in nursing education. These ideas initiated a journey of discovery, attempting to uncover not only what had transpired, but more importantly what had inspired educational innovations. Current day Canadian nursing curricula are virtually devoid of teaching the history of the profession of nursing (Toman \& Thifault, 2012), which is a departure from previous practice in which the history of the profession and of individual schools was not only taught but celebrated (Grypma, 2017). Many students and faculty alike are not aware of the overall history of the nursing profession, let alone their own school's history. By ignoring its rich history, nursing runs the risk of constantly reinventing itself with a concomitant lack of social recognition for the profession (Nelson \& Gordon, 2004). An indepth examination of one school's history could shed light on the conditions that fostered educational scholarship and practice.

A comprehensive historical analysis was undertaken and a book exploring the history of the SON (1946-2016) is nearing completion. While the book includes several themes for which there is evidence of the school's nursing education scholarship, this article focuses on the historical evolution of three highly interrelated aspects of educational approaches: problem-based learning, evidence based nursing, and academic/community partnerships. The paper further traces the influences on and of these approaches, set within the context of major events of the SON, and includes key lessons learned in conducting institutionally based historical analysis. "Tracking the trends of issues across decades can help us to map out a trajectory towards a likely future" (Grypma, 2017, p. 9). One institution's history may provide a compass to navigate current day challenges and orient future strategies in the continued pursuit of excellence in nursing education.

\section{Background}

The history of nursing and nursing education in Canada is well documented elsewhere (see, for example, Baker et al., 2012; Bates et al., 2005; Mansell, 2004; McPherson, 1996) although a brief review of the evolution is helpful to set the context for this institutionally based historical analysis. The Mack Training School in St. Catharines, Ontario, was the first formal hospital-based nursing education program to be established in Canada in 1874 (Baker et al., 2012). While other hospital training programs emerged shortly thereafter, their quality varied widely based on the size of the hospital and the importance placed on nursing education by the physician hospital administrators. The emphasis was mainly on students providing cost effective nursing care rather than on education (McPherson, 1996). The Weir Report of 1930, which was largely not implemented, and the later Hall Report of 1964, both recommended substantial changes in nursing education in the entire country. Following the Hall Report recommendations that $75 \%$ of registered nurses be educated at the diploma level within educational institutions, nursing schools began to move from the hospitals to the newly emerging community college system in the 1970s and 1980s (Elliott et al., 2013). However, it was not until 1998 that the Vancouver City Hospital Training School, the last hospital-based school, closed (Baker et al., 2012).

The 1910 Flexner Report on medical education in the United States prompted the move of physician training to universities in the Unites States and Canada, and nursing leaders proposed a similar move for nursing education. The University of British Columbia opened the first five-year 
baccalaureate nursing program in Canada in 1919, with the University of Western Ontario and the University of Alberta opening in 1924 (Baker et al., 2012; University of Alberta, 2020). There was a clear growth in the number of university-based programs for nursing, although enrollment numbers were consistently very low. The focus of these university programs was to educate the teachers, administrators, and public health nurses, rather than to train the bulk of nurses entering the profession (Baker et al., 2012).

Virtually all historical accounts of Canadian nursing cited above mark World War II as a turning point for nursing education. There was recognition of the contributions that nurses had made during the conflict, and there was greater public valuing of nursing. At the same time, there was a clear shortage of nurses and other health care professionals, prompting renewed interest in the quality of nursing education (McPherson, 1996). At the beginning of the 1940s there were five baccalaureate programs and two university-based diploma programs in Canada. By the end of the decade, McMaster University joined four other universities in offering baccalaureate education in nursing (Baker et al., 2012).

Nursing curricula within hospital, community college, and most baccalaureate nursing programs in Canada through the 1970s and beyond were often structured using Tylerian behavioural objectives, with a focus on mastering technical skills. In subsequent decades, there was a gradual shift toward more student-centred and critically reflective approaches within higher education generally, and nursing education more specifically (see for example, Bevis \& Watson, 1989; Brookfield, 1987). A significant milestone was achieved when a baccalaureate degree became the minimum for entry to practice in the mid-2000s, with provinces adopting this requirement at slightly different times over a 10 -year period. Community college and university programs formed partnerships to meet this requirement and collaborative programs became the most common form of registered nursing education in Canada (Kirby, 2008).

Graduate-level education in nursing developed more slowly in Canada, lagging behind other jurisdictions, particularly the United States. In the early days, many Canadian nursing academics were either educated in the United States or in programs other than nursing (Baumgart \& Larsen, 1992; Ross-Kerr, 2003). The first graduate program in nursing in Canada opened in 1957 at the University of Western Ontario at the master's level. In 1962, the Canadian Nurses Association passed a resolution calling for the establishment of master's and doctoral programs in nursing, and for directors of baccalaureate schools of nursing to be prepared at least at the master's level (Ross-Kerr, 2003). In 1987, there were 11 master's level programs (Baumgart \& Larson, 1992), and by 2016, 30 master's programs were established, spanning 10 provinces. It was not until 1991 that the University of Alberta was fully funded to open the first PhD program in nursing (Thorne, 2019). By 2016, there were 16 Canadian PhD programs in nursing (Thorne, 2019). At McMaster University, an interprofessional master's in clinical practice was offered from 1973 to 1993, and master's and doctoral programs in nursing were established in 1994.

Approaches to nursing education are well documented in the literature, as indicated by the substantial number of nursing educational journals, some of which have been in existence for over 50 years. For example, the Journal of Nursing Education, the Journal of Nursing Education and Practice, the International Journal of Nursing Education Scholarship, and the Quality Advancement of Nursing Education, routinely publish nursing educational scholarship and research. However, there have been repeated calls to improve the quality of nursing educational research (Morton, 2017), and few studies have used a historical research lens to evaluate nursing educational approaches. The limited number of articles published between 1990 and 2020 that 
trace the evolution of nursing education approaches beyond descriptions of individual schools or programs have provided retrospective literature reviews on the development of such topics as concept maps, evidenced based nursing, or critical thinking (Simpson \& Courtney, 2002). Other examples have included analyses of archival documents (Kako \& Rudge, 2008; Walker \& Holmes, 2008), have offered overviews of national historical trends (Baer, 2012; Mathisen \& Bastoe, 2008), or have discussed the value of historical research for nursing education (Keating, 2016; Nelson \& Gordon, 2004). To better understand our own history, we decided to conduct a historical analysis of nursing educational scholarship undertaken at our SON over its 70-year history, critically examining the factors influencing the educational approaches taken and the perceived impact of those approaches.

\section{Historical Analytical Approach}

Historical research does not have one set, structured methodology and is flexible, contingent upon the purpose of the study (D'Antonio \& Lewenson, 2011). Danto's (2009) descriptive historiography approach was used in this study. This approach entailed compiling a chronological catalogue of evidences of educational scholarship and of major events that occurred within the SON from 1946 to 2016. It also included a cultural historiography lens that uses a cultural framework to help explain influences on and of the SON activities (Danto, 2009).

As recommended for historical research, information was gathered from multiple sources (Rocco et al., 1998), including oral histories from 23 key informants, materials written by and about past key events and individuals and events within the SON and beyond, and institutional records from various archives. An extensive and detailed literature search was conducted of SON educational scholarship, and evidences found were categorized and analyzed by a minimum of two researchers. The themes identified in the literature review for SON educational scholarship contributions informed the questions of the oral histories. As oral histories were conducted, topics and themes emerged which led to more focused archival searches and additional lines of enquiry. Research ethics approval for the entire project was granted by the Hamilton Integrated Research Ethics Board. In historical research, it is frequently the practice to attribute specific information to key informants (Oral History Association, 2018), rather than protecting the anonymity of participants as in other quantitative and qualitative approaches. All key informants were invited to identify transcript areas in which they would choose to remain anonymous. A tiered approach to consent was used (Liu \& Hu, 2014) to address informed consent of future uses. Care was taken to ensure that no details of sensitive material were included in the study. A more detailed description of sources and data analysis is supplied as supplemental material.

\section{Evolution of the McMaster School of Nursing}

Based on the massive amount of data we obtained, many themes emerged, with a focus on how educational approaches and endeavours evolved over the 70 years. Themes that have focused on educational scholarship included philosophical approaches, curriculum design, program evaluation, clinical excellence in nursing education, academic community partnerships, models of faculty appointments and supports, specific educational approaches such as problem-based learning and evidence-based nursing, and students' experience. Different time-limited educational endeavours such as clinical specialty programs, nurse practitioner programs, and collaborative programs were traced, including rationales for starting and stopping programs, as well as an analysis of what and how they contributed to nursing practice. The contributions of the evolving nurse scientist role on nursing education and international outreach and partnerships were 
identified. All of these themes have been supported by scholarship and/or educational research. While these many areas are fascinating for those closely associated with the SON, this article focuses on three themes related to educational scholarship in which the McMaster SON was an early leader: problem-based learning, evidence-based approaches, and academic/community partnerships. These three areas were developed primarily in the late 1970s but the genesis for the ideas can be found further back in the SON's beginnings. A table outlining major events of the $\mathrm{SON}$ is available in the supplemental material for those interested.

To set the context for exploring the three themes, it is helpful to first have a very brief review of the overall history of the SON. The McMaster SON was founded in the Faculty of Science in 1946. The bachelor of science in nursing (BScN) was offered in an integrated fashion, with the SON retaining control over the curriculum and delivery of all five years of the program. Thus, the importance of integrating theoretical and clinical nursing knowledge was present from the beginning of the BScN program. The school grew slowly over the next 20 years, with a focus on the scientific and humanistic basis for nursing practice, on the social aspects of health promotion, and on the development of self-directed learning. By the 1960s, there was significant pressure for the expansion of baccalaureate education, and the SON was highly involved with the Hamilton Academy of Medicine in planning the eventual Faculty of Health Sciences and the new on-campus hospital, the McMaster University Medical Centre. ${ }^{1}$ Nursing clearly benefited from its partnership with medicine in terms of opportunities for collaborative research, greater access to funding, and access to faculty development programs with national and international experts in education. Nursing embraced the ideas of problem-based learning and evidence-based practice that originated with the early leaders of the School of Medicine at McMaster and modified these to address the unique needs of nursing. ${ }^{2}$ There were also costs associated with joining a faculty in which medicine overshadowed all other partners, echoing the well-documented place of nursing in relation to medicine (Mansell, 2004; McPherson, 1996; Muff, 1982). The influences of joining the Faculty of Health Sciences can be seen in the ensuing nearly 50 years within the three themes explored below.

\section{Theme 1: Problem-Based Learning (PBL)}

Problem based learning (PBL) is a constructivist learning approach whereby students guide the learning process and learn about a subject by working in groups and using andragogical principles. One of the basic tenets of problem-based learning is that it is student-centred and selfdirected (Barrows \& Tamblyn, 1980).

From the earliest beginnings of the School of Nursing in 1946, nursing classes were small. This was a natural outcome of the small numbers of students enrolled in the program. "Students were encouraged to talk freely, to discuss openly, to defend their ideas, and to offer positive constructive criticism" (Alderson, 1976, p. 265). Nursing used an overall approach of enquiry, active learning, and self-directed learning before the adoption of problem-based learning decades later. As a graduate of the class of 1957 shared, "Even way back then, self-directed learning was

\footnotetext{
${ }^{1}$ The naming of the McMaster University Medical Centre (MUMC) met with the recorded protest of several nursing faculty, as this was not in keeping with the interdisciplinary nature of the planned health science approach. Greenlee (2015), in his history of McMaster University referred to this as a "teapot tempest," which "soon blew over" (p. 168). The letters by nursing faculty are located in the McMaster University Archives.

${ }^{2}$ Summarized from SON annual reports (1946-1997), SON periodic reports (1990-2014), accreditation self-study reports (1989, 1997, 2004, 2014), Alderson (1976), and DiCenso et al. (2005). All reports are located in Faculty of Health Sciences Archives, McMaster University.
} 
a phrase that was used a lot on campus." ${ }^{3}$ While no archival records were found with the term selfdirected learning from this period, records from the time demonstrate an openness to moving away from a didactic teacher-based approach to learning.

The major shift to PBL came as the SON joined the Faculty of Health Sciences, in the late 1960s and 1970s. It is clear that the newly formed School of Medicine was the leader in developing the process of PBL (Servant, 2016), and the faculty in the SON were influenced by this new approach. While there is evidence of interprofessional collaboration between nursing and medicine during this developmental period, and then later with the School of Rehabilitation Sciences, any contributions that nursing may have made to the thinking of the medical faculty were not recorded. This is also consistent with the Greenlee's (2015) history of McMaster, which detailed the developments within various faculties and departments from 1957 to 1987 . The book contains a full chapter on the development of the medical school but only one passing phrase noting "the thriving School of Nursing founded in 1946" (p. 140) during the same time period. Meanwhile, the School of Nursing annual reports for that time were full of details of its involvement in planning. Nursing was indeed overshadowed by medicine.

In the 1960s, the SON was already ahead in relation to student engagement in the learning process; but it decided to shift paradigms to accept the new PBL approach. Nursing had to adapt and modify its existing curriculum, rather than create something new as medicine was doing. Furthermore, the funding models for medical education were far more generous, and nursing could simply not afford to have all courses offered in a PBL format within small groups of six to eight students. Thus, nursing adopted a hybrid model, with one nursing course per term offered within the PBL format and other courses, such as anatomy and physiology, offered in more traditional lecture formats. ${ }^{4}$ For many years, the various associate deans and directors of the School of Nursing became adept at finding "soft money" through various projects to support the continuation of the PBL model of education.

On the other hand, as indicated earlier, self-directed learning, as a major component of PBL, was not a new idea at the SON, although the actual term may not have been coined until the 1970s. Several of the newly hired nursing faculty had completed their master's in nursing at Boston University, where Malcolm Knowles, the father of self-directed learning was teaching. ${ }^{5}$ The extent of Malcolm Knowles's influence on the nursing curriculum cannot be understated. Following its publication in 1975, Knowles's text, Self-Directed Learning: A Guide for Learners and Teachers (Knowles, 1975) was required reading for all new faculty and all students. The PBL approach was underpinned by the notion that students would be actively engaged in their own learning. However, not everyone was happy with this approach. "Faculty were angry, and the students were angry. One day we came to school and the students had put banners up, and the faculty there were with them, like down with Malcolm [Knowles]."

By 1971, the shift to problem-based, self-directed, small group learning was well underway. However, it was initially called the "problem-solving approach" rather than problembased learning. ${ }^{7}$ This is consistent with the findings of Servant (2016) who did not find any reference to the phrase problem-based learning until 1974, four years after its adoption by the

\footnotetext{
${ }^{3}$ Margaret McGovern, key informant interview, February 2019.

${ }^{4}$ Undergraduate calendars and course manuals, 1970-1980.

5 Joan Crook and Robin Weir, key informant interview, December 2019; selected faculty CVs.

${ }^{6}$ Olga Roman, key informant interview, December 2016.

${ }^{7}$ SON annual report (1970-1971).
} 
McMaster University medical school. The approach with its distinctive learning cycle was then formalized in publications starting from the mid-1970s onwards. (See, for example, Barrows \& Tamblyn, 1980; Neufeld \& Barrows, 1974). While there are slight variations found within the literature on PBL, the steps as implemented by the SON included: "1) the problem is presented to the group, terms are reviewed, and hypotheses generated; 2) learning issues and information sources are identified; 3) information is gathered and independent study occurs; 4) knowledge acquired is discussed and debated critically; 5) knowledge is applied to the problem in a practical way; and 6) reflection on the content and process of learning occurs" (Rideout \& Carpio, 2001, p. 29).

The process of PBL was well established in the SON by the late 1970s and continued virtually unchanged for decades. However, the patient scenarios that prompted the learning were frequently modified or replaced based on emerging health trends, issues, and evidence (Arthur \& Baumann, 1996). The McMaster School of Medicine soon became world famous for this educational innovation (Frenk et al., 2010). The SON also became known for PBL but did not attain the level of fame of the School of Medicine in the published literature. Nursing faculty mainly shared their knowledge through consultations, presentations, and visiting professorships, although they also published in nursing journals.

As a prior director of the SON stated: "We had to justify problem-based learning. We did that. But we didn't write enough about it. But we certainly did [share] in conferences. We demonstrated it in workshops. We brought people over to show the value. We had volunteered to be accredited. . . . But I think we could have reached a larger audience." 8 It is nearly impossible to capture these person-to-person events as there was no systematic recording of them. However, from the 1970s to the 1990s, nearly all full-time faculty shared information about PBL with others, including in multiple countries spanning the globe. ${ }^{9}$

Despite the perception of decreased external impact when compared with the School of Medicine, faculty did publish on PBL and a sampling of the many peer-reviewed publications and/or books and book chapters included topics ranging from early descriptions of the process (Von Schilling, 1973, 1982) to evaluating the effectiveness of PBL contrasted with other approaches (Bouchard \& Steels, 1980; Glanville et al., 1976; Majumdar et al., 1998; Rideout et al., 2002), and to different aspects of PBL such as the creation of evidence based tutorial evaluation forms (Ladouceur et al., 2004), the exploration of student experiences, including self-confidence and emotional intelligence (Benson et al., 2012; Lunyk-Child et al., 2001; Majumdar, 1999), and the role of the tutor (Matthew-Maich et al., 2016). Faculty also co-authored a book on PBL that provided details of various aspects of the implementation process (Rideout, 2001).

It is a challenge to find linear relationships in the spread of educational approaches (Rolfe \& Gardner, 2006). However, there are evidences of national and international exchanges and relationships that have contributed to nursing education's adoption of the PBL approach. In every decade since the adoption of PBL, the SON has attracted visitors from other nursing programs (e.g., Australia, Hong Kong, India, New Zealand, South Africa, South Korea, Thailand, Turkey, the United Kingdom, and the United States). A search of the literature, which is available in the supplemental material, found that PBL curricula are present in many nursing programs in the world, some very likely influenced by their visits to McMaster.

\footnotetext{
${ }^{8}$ Susan French, key informant interview, February 2017.

${ }^{9}$ SON annual reports (1970-1990); select faculty CVs.
} 
In the 1990s McMaster nursing professor Karen Von Schilling received an honorary doctorate from the University of Linkoping, Sweden, recognizing her contribution of the PBL approach to nursing education in that country. Another example of the direct and indirect impacts of the McMaster SON was its 22-year relationship with the School of Nursing at the Aga Khan University (AKU) in Pakistan. The AKU Pakistan then seeded the PBL nursing approach across the Aga Khan health system to India, Kenya, Uganda, and Tanzania. A range of activities from projects with universities in Chile, Mexico, Sharjah, South Africa, and the West Indies to the McMaster summer institutes with faculty attending in groups from other countries such as Thailand and Japan has helped faculty in each setting understand the McMaster PBL model of nursing education and how they might adapt the model to best suit their nursing program and local health needs. ${ }^{10}$

Over time, internal and external pressures led to significant modifications to the PBL approach. Between the 1990s and 2012, group sizes for PBL increased to 20 students on average, because of financial pressures. ${ }^{11}$ Tutorials were then structured with small breakout groups of five students within the larger group of 20 , with class time alternating between the two structures. This design retained the benefits of group work and active learning while also allowing for tutor facilitation and monitoring of the learning process. The shift was piloted and evaluated before being rolled out across the entire program (Mujica \& Pierazzo, 2012).

Other modifications to the PBL approach included increased supports for faculty tutors as the size of the SON increased, the introduction of technology and learning platforms to enhance or, at times, replace in-class learning, and the development of rich multimedia narratives to introduce scenarios to focus students' attention on the person at the centre of the learning "problem."

From the time of adopting PBL as the dominant educational approach, the SON was committed to sharing nursing-specific knowledge of the approach, as well as conducting educational research on different aspects of PBL. The collaborations with the McMaster Schools of Medicine and Rehabilitation Sciences continued throughout this period, especially in sharing resources and expertise. The philosophies embedded within the approach influenced how all other courses were offered, shaping the educational experiences of students.

\section{Theme 2: Evidence-Based Nursing}

The development of critical appraisal of the literature was a natural partner to problembased learning. The PBL process described above includes students independently seeking information and then critically debating their information within the tutorial group. The question then was how to find the best information and how to critically analyze that information. Over time this process evolved into evidence-based practice and, most recently, evidence-informed decision making. The overall approach in thinking is referred to as evidence-based nursing (EBN) in this article.

Within the Faculty of Health Sciences, the Design Measurement and Evaluation program of the Department of Clinical Epidemiology and Biostatistics was founded in 1972. It offered graduate-level education with an interprofessional focus and housed experts in health science

\footnotetext{
${ }^{10}$ SON annual reports (1967-1997), SON periodic reports (1990-2014), accreditation self-study reports (1989, 1997, 2004, 2014), and multiple archival documents.

${ }^{11}$ SON annual reports $(1980,2007)$.
} 
research design (Health Research Methodology, n.d.). As the science of research methodology was burgeoning from the 1980s onward (Guyatt et al., 2004; Sackett, 2015) several SON faculty completed their master's degrees here. As one key informant remembered, "both 'A' and I took Critical Appraisal in the Design Measurement and Evaluation course for our Masters ... and I don't know how it came about, but the thought was this should be taught in the Bachelor program for all health professionals. And we thought why wouldn't we give it to every student nurse? It was so important that if you could understand research, learn about it, start to dissect it, then you might start thinking about doing and utilizing research." ${ }^{2}$ McMaster University "is widely acknowledged as the home of evidence-based medicine" and housed the original Canadian Cochrane Centre when it was established in 1993 (Cochrane Canada, n.d.). Thus, it is not surprising that many of the SON faculty took advantage of these interprofessional connections, holding cross appointments with the department and working on Cochrane projects. ${ }^{13}$

Nursing faculty developed a required critical appraisal of the research literature course for all $\mathrm{BScN}$ students by the late 1980s. Within this course, students learned to assess the quality of published literature on major study designs such as randomized control trials or cohort studies. The course was also offered at local hospitals to practising nurses who used it as a first course toward a post-RN BScN. The background knowledge of how to evaluate the research literature was fundamental to supporting EBN.

At that time, nursing research was still relatively new and to actively involve students in current research projects of SON faculty, a required fourth-year BScN course was devised. The course included a poster presentation of the students' role in their project. Many projects were based on the relationships with the local nursing practice community. ${ }^{14}$ One alumnus remembered, "those experiences at McMaster led me to practice with a healthy dose of questioning why we did what we did. ... It gave me the tools to at least ask why are we doing it this way? And what does the research say about doing it this way?" 15 Thus, there was evidence of the interrelationship between problem-based learning and the courses that reinforced evidence-based nursing practice.

Rolfe and Gardner (2006) suggest that the development of evidence-based nursing is not linear, but that there were multiple influences. They acknowledge Dr. David Sackett at McMaster as the originator of evidence-based medicine and further critique the writings of SON faculty as they were so often cited by others as experts on evidence-based nursing. Our historical analysis has provided evidence that the McMaster SON became a leader in evidence-based nursing, with two faculty members serving as inaugural co-editors for the journal Evidence Based Nursing, founded in 1993 by the BMJ publishing group. These two leaders were also co-authors on two important evidence-based nursing texts (Cullum et al., 2008; DiCenso et al., 2005). Aside from the burgeoning publications on clinical nursing research and research methodology, the establishment of different chairs in nursing furthered the research capacity of graduate level students in cardiovascular nursing, advance practice nursing, and health services and policy research. These initiatives built from and added to the relevance of evidence-based nursing. ${ }^{16}$

\footnotetext{
12 Jackie Roberts, key informant interview, February 2018.

${ }^{13}$ Select faculty CVs.

${ }^{14}$ Accreditation self-study reports (1989, 1997); Jackie Roberts, key informant interview, February 2018.

${ }^{15}$ Maureen Dobbins, key informant interview, February 2019.

${ }^{16}$ Alba DiCenso (November 201), Andrea Baumann (December 2018), Jackie Roberts (February 2019), key informant interviews; select faculty CVs; multiple archival documents.
} 
It is now commonplace to expect evidence to inform decision making in virtually all aspects of nursing, medicine, governmental policies, etc. Nursing at McMaster was a very early adopter of teaching students how to obtain, evaluate, and apply evidence to their developing practice. While there have been numerous faculty development opportunities within McMaster's SON over many years to support critical appraisal development skills, our challenge had been and continues to be ensuring that all faculty are adept at critical appraisal so that this skill is reinforced in all theory and practice courses. We have attributed these challenges to various reasons, including the hiring of part-time instructors who teach specific clinical courses rather than full-time faculty who teach across the undergraduate program, lack of faculty expertise in EBN and/or strategies to teach it, and the move to larger class sizes in PBL, which limits the capacity for rich discussion of the underlying evidence. The challenges that we have experienced are cited by others, including the need to carefully align the discussion of EBN concepts to coincide with students' level of learning and understanding of the clinical context (Ramis et al., 2018), continually integrate clinical and academic EBN concepts throughout the curriculum (Brown et al., 2010), and train nursing faculty to improve their knowledge of critical appraisal and/or EBN teaching strategies (Hornvedt et al., 2018). Despite the challenges, learning the principles and application of evidencebased nursing has been an enduring strength for graduates of the McMaster program.

\section{Theme 3: Academic/Community Partnerships}

Since its earliest days, the SON had a well-established practice of partnering with the community at the local, national, and international level. There are numerous examples of projects and ongoing relationships that occurred between the SON and community agencies, hospitals, or different groups of individuals. The range of partnerships varied widely, depending upon the purpose for both partners, and greatly influenced all aspects of educational scholarship of the SON. Two of the many possible examples are described here.

Different models of faculty appointments fostered partnerships. The first recorded crossclinical appointment for nursing was between the McMaster Family Practice Unit, the Chedoke McMaster Hospital, and the SON in $1969 .{ }^{17}$ Joint cost-shared faculty appointments were first recorded in 1976 with a goal of strengthening ties between academia and the clinical settings. ${ }^{18}$ These positions facilitated academic nursing research that was relevant to local practice issues, while ensuring that faculty would stay current in their nursing knowledge and that practice settings could benefit from highly skilled and educated nurses. These appointments reached their zenith with the establishment of the Public Health Research, Education and Development Program (PHRED) in 1983 and included all local hospitals and many community agencies. The challenge in maintaining these cost-shared appointments arose from the disparate funding models between education and care provider institutions. Unlike medicine, where physicians could direct bill for services provided, nursing positions were built into existing hospital or community administrative structures. When the hospitals began restructuring, advanced practice nursing roles, such as clinical nurse specialists, were quickly on the chopping block, eliminating the clinical half of the joint appointment. This pattern was echoed in the community when a new medical officer of health eliminated the nursing research roles in PHRED. Thus, these positions largely disappeared by the late 1990 s or early 2000 s. $^{19}$

\footnotetext{
${ }^{17}$ SON annual report (1968-1969).

${ }^{18}$ SON annual report (1976-1977).

${ }^{19}$ SON status report (2003-2008); Andrea Baumann, key informant interview, December 2018.
} 
Community partners also supported their own master's-prepared nurses to have clinical (part-time, unpaid) faculty appointments in the SON where they contributed to curriculum development and direct teaching of students. With predicted shortages of nurses (Pringle et al., 2004), local hospitals were keen to assist the SON in increasing its student enrollment capacity, as well as furthering the education of their diploma-prepared nurses. Clinical appointments increased significantly when the post-RN program began in 1982. The close connections with the community identified the needs for specialty educational programs for diploma-prepared nurses and led to shared space for education and practice. The partnerships supported the development of PBL scenarios and research practicum opportunities for students. Many clinical faculty met the requirements for their faculty appointment by tutoring final year students in their preceptored clinical placements that were occurring in the faculty's own clinical settings, which provided students with the opportunity to learn from expert nurses in the practice setting. The appointments also provided opportunities for clinical faculty to engage with university-based nursing faculty to expand their own research capabilities. The SON historically has had over 250 clinical faculty appointees and over 30 faculty with joint appointments.

The 2000s onward have seen a shift in the partnerships. Practice settings no longer had the funds to support the previous collaborative models. As well, as nursing research had matured, different academic partnerships developed within the university, as opposed to being primarily with nursing colleagues, to meet the criteria of the primary research funders such as the Canadian Institutes of Health Research or Social Sciences and Humanities Research Council of Canada. At times, there have been funding programs designed to promote nursing research, although these have been inconsistent and have not necessarily focused on those areas central to the "softer" areas of nursing expertise. As stated by one of the key informants who has been highly successful in research, "I think the status of nursing continues to be a challenge. I think the dominance of the medical paradigm, the way health care is envisaged by most communities and societies [results in] the de-emphasis of caring, the scientific basis of caring. And I'm not sure how far we've come on that. And then also the challenge is really support for what I call nursing research. I think actually that has been subsumed under health services. If you look even in my career as a researcher, I've had to deviate from my core expertise, because if I was to design a study that would talk about nursing care and caring, you would never get funded." While there has been significant success in research output of the SON, the changing requirements have also resulted in fewer close connections with local practising nurses. Have we sacrificed our connections to the bedside in our efforts to seek greater interdisciplinary recognition?

\section{Discussion}

Several lessons were uncovered by this historical analysis, including ways to build on existing strengths while being open to opportunities, the impact of organizational culture, the use of a proactive planning approach, and the exponential effect of innovations. A cautionary lesson on nursing's voice in promoting its own knowledge was also uncovered. As well, lessons were learned through the application of the historical methodology.

The move of the SON to the Faculty of Health Sciences in the 1970s ushered in the possibility of enhanced interprofessional collaboration, as well as the expansion of the student and faculty complement. It is undeniable that the close ties with the new and innovative School of Medicine provided unprecedented opportunities to move beyond the forward-thinking educational approaches already employed within the SON. The innovations of problem-based learning and evidence-based nursing went hand in hand to support an established culture of enquiry in students 
and faculty alike. Furthermore, nursing faculty benefitted from the growing research expertise within the medical community, particularly given the paucity of nursing graduate education. Closer ties to the nursing practice community developed, as a new hospital was built on the university grounds, and the SON faculty were heavily involved in planning the approaches to clinical practice. Although not without challenges, this time of immense change was seen as an opportunity rather than merely as a threat to the existing structure and function of the SON.

The culture of risk-taking and idea sharing was a product of the times in the 1970s and faculty members were willing to share generously with each other. Where medicine was a leader, they provided ideas, resources, and support to nursing. Success with any innovation is not a given, and the organizational culture at McMaster University was one of openness to feedback so that modifications to the approaches were expected. This culture of learning from educational research to improve the curriculum carried forward for decades. Educational research was valued, with some financial support available at the faculty and university levels with nearly all nursing faculty engaging in some type of educational research. In 1995, the SON established and funded the Nursing Education Research Unit to further excellence in educational research, addressing chronic funding challenges and providing invaluable support. ${ }^{20}$ Problem-based learning and evidencebased nursing evolved with this research.

Community partnerships were planned proactively from the earliest days of the SON in 1946 and have remained core to its identity and success. Problem-based learning and evidencebased nursing were also planned proactively rather than reactively to external events. These three have remained core components of the SON. When reactive changes have been required for issues such as financial pressures or size of the student body and faculty complement, the question has always been how to retain the essence of these core components. Ensuring the centrality of an educational innovation means that it is more likely to endure when faced with new challenges. The recent promotion of community-engaged learning in higher education in general (Butin, 2012) could benefit from nursing's long history of successes in this area, yet it is rare to find nursing publishing in this area outside of nursing journals.

The interrelatedness of the three themes has been highlighted by this historical analysis. When faculty are teaching in one or two discrete courses, they may be less aware of the overall curriculum. If faculty have a good understanding of how major themes developed, they can then communicate these to students for a greater understanding of the rationale for what and how they are learning. Highlighting the interconnection between the themes can also help bridge academic and clinical learning and practice. Thus, understanding the foundations of any educational approach is important.

The SON has received international recognition within the nursing community, particularly for PBL. However, this recognition has been eclipsed by faculty in the School of Medicine. Experts most likely to be cited on PBL or evidence-based practice are from medicine, not nursing. This historical analysis found that nursing faculty were more likely to share their knowledge through face to face interactions at conferences or through visiting professorships, and their influence was indirect and harder to trace. Nursing's primarily female voices within interdisciplinary meetings were not recorded, echoing patterns that feminist authors have decried for years (Gluck \& Patai,

\footnotetext{
${ }^{20}$ Andrea Baumann (December 2018), Charlotte Noesgaard (April 2017), Elizabeth Rideout (January 2017), key informant interviews; SON biennial report of scholarly activities (1996).
} 
2016; Scanlon, 1993). Furthermore, the development of ideas is complex, and a linear progression is not likely to be found (Rolfe \& Gardner, 2006).

Lessons were also learned from the process of conducting historical research. The research team included a part-time faculty member with a $\mathrm{PhD}$ in history during the first year. University archivists were invaluable in assisting with locating relevant material. Still, finding details of what occurred and what influenced events was similar to a treasure hunt, with many false starts and sometimes surprising finds. Ensuring that there is a comprehensive plan for transferring relevant reports to institutional archives is critical for future historians. As well, using a tiered approach to consent for retaining key informant interviews should be considered. While human resource departments may advise that personnel records be destroyed after seven years, retaining a comprehensive record of faculty is important. This is further complicated as the primarily female faculty experienced interruptions of service for educational, parental, or other leaves and/or changed names related to marital status. The challenges were more than outweighed by the new understandings that emerged in the process.

\section{Conclusion}

Rather than constantly reinventing itself, nursing needs to honour its foundations (Nelson $\&$ Gordon, 2004). This historical analysis of one school of nursing's educational scholarship has provided insights in terms of understanding the forces that have shaped its educational approaches and how this history orients the thinking on educational changes proposed in response to ongoing challenges. It is important to be open to opportunities and have an institutional culture supportive of risk taking. Risk taking can inspire innovation. We are currently in a time of greater global awareness of the importance of nursing given the SARS-CoV-2 (COVID-19) pandemic. Following World War II, nursing was proactive in making great strides in education and practice. The 1970s were a time of great cultural upheaval and also of innovations in education generally and nursing specifically. Will we learn from the past and use the period once the pandemic has passed to make similar leaps forward in nursing education and practice for the betterment of health for all? 


\section{References}

Alderson, H. J. (1976). Twenty-five years a-growing. McMaster University.

Arthur, H., \& Baumann, A. (1996). Nursing curriculum content: An innovative decision-making process to define priorities. Nursing Education Today, 16(1), 63-68. https://doi.org/10.1016/s0260-6917(96)80095-5

Baer, E. D. (2012). Key ideas in nursing's first century. AJN American Journal of Nursing, 112(5), 48-55. https://doi.org/10.1097/01.NAJ.0000414321.10073.c8

Baker, C., Guest, E., Jorgenson, L., Crosby, K., \& Boyd, J. (2012). Ties that bind: The evolution of education for professional nursing in Canada from the 17th to the 21st century. Canadian Association of Schools of Nursing. https://www.casn.ca/wpcontent/uploads/2016/12/History.pdf

Barrows, H. S., \& Tamblyn, R. M. (1980). Problem-based learning: An approach to medical education. Springer.

Bates, C., Dodd, D., \& Rousseau, N. (Eds.). (2005). On all frontiers: Four centuries of Canadian nursing. University of Ottawa Press.

Baumgart, A. J., \& Larsen, J. (Eds.). (1992). Canadian nursing faces the future (2nd ed.). Mosby.

Benson, G., Martin, L., Ploeg, J., \& Wessel, J. (2012). Longitudinal study of emotional intelligence, leadership, and caring in undergraduate nursing Students. Journal of Nursing Education, 51(2), 95-101. https://doi.org/10.3928/01484834-20120113-01

Bevis, E. O., \& Watson, J. (1989). Toward a caring curriculum: A new pedagogy for nursing. NLN.

Brookfield, S. D. (1987). Developing critical thinkers: Challenging adults to explore alternative ways of thinking and acting. Jossey-Bass.

Bouchard, J., \& Steels, M. (1980). Contrast learning: The experience of two nursing schools. Canadian Nurse, 76(1), 44-48.

Brown, C. E., Kim, S. C., Stichler, J. F., \& Fields, W. (2010). Predictors of knowledge, attitudes, use and future use of evidence-based practice among baccalaureate nursing students at two universities. Nurse Education Today, 30(6), 521-527. https://doi.org/10.1016/j.nedt.2009.10.021

Butin, D. W. (2012). Rethinking the "apprenticeship of liberty": The case for academic programs in community engagement in higher education. Journal of College \& Character, 13(1), $1-8$.

Cochrane Canada. (n.d.). Michael G. DeGroote Canada Cochrane Centre. https://canada.cochrane.org/about-us/micheal-g-degroote-cochrane-canada-centre

Cullum, N., Ciliska, D., Haynes, R. B., \& Marks, S. (Eds.). (2008). Evidence-based nursing: An introduction. Blackwell Publishing.

D’Antonio, P., \& Lewenson, S. (Eds.). (2011). History as evidence: Nursing interventions through time. Springer. 
Danto, E. A. (2009). Historical research. Oxford Scholarship Online. https://doi.org/10.1093/acprof:oso/9780195333060.001.0001

DiCenso, A., Guyatt, G., \& Ciliska, D. (2005). Evidence-based nursing: A guide to clinical practice. Mosby.

Elliott, J., Rutty, C., \& Villeneuve, M. (2013). Canadian Nurses Association: One hundred years of service. Canadian Nurses Association. https://www.cna-aiic.ca/-/media/cna/pagecontent/pdfen/cna_history book_e.pdf?la=en\&hash=FEDD37A0DE38667A724FC63A275AEF3B9 9A48674

Frenk, J., Chen, L., Bhutta, Z. A., Cohen, J., Crisp, N., Evans, T., Fineberg, H., Garcia, P., Ke, Y., Kelley, P., Meleis, A., Naylor, D., Pablos-Mendez, A., Reddy, S., Scrimshaw, S., Sepulveda, J., Serwadda, D., \& Zurayk, H. (2010). Health professionals for a new century: Transforming education to strengthen health systems in an interdependent world. The Lancet, 376, 1923-1958.

Glanville, C., Feldman, E., Crook, J., \& Katada, D. (1976). A comparison of two types of learning experience in a second year nursing course. Nursing Papers: Perspective on Nursing, 9, $112-119$.

Gluck, S. B., \& Patai, D. (Eds.). (2016). Women's words: The feminist practice of oral history. Routledge.

Greenlee, J. G. (2015). McMaster University, Volume 3, 1957-1987: A chance for greatness. McGill-Queen's University Press.

Grypma, S. (2017). Historically informed nursing: The untapped potential of history in nursing education. Quality Advancement in Nursing Education-Avancées en formation infirmière, 3(1), Article 2. https://doi.org/10.17483/2368-6669.1099

Guyatt, G., Cook, D., \& Haynes, B. (2004). Evidence medicine has come a long way: The second decade will be as exciting as the first. BMJ British Medical Journal, 329(7473), 990-991.

Health Research Methodology. (n.d.). Health research methodology (HRM) program history. Faculty of Health Sciences, McMaster University. https://healthsci.mcmaster.ca/heihrm/about-us/history

Hornvedt, M. T., Nordstein, A., Fermann, T., \& Severinsson, E. (2018). Strategies for teaching evidence-based practice in nursing education: A thematic literature review. BMC Medical Education, 18, 172. https://doi.org/10.1186/s12909-018-1278-Z

Kako, M., \& Rudge, T. (2008). Governing nursing: Curriculum as a rhetorical vehicle using South Australian nursing schools from the 1950s onwards as an illustrative case. Contemporary Nurse: A Journal for the Australian Nursing Profession, 30(2), 142155. https://doi.org/10.5172/conu.673.30.2.142 
Keating, S. B. (2016). Looking back to the future: Current issues facing nursing education from the reflections of a member of the silent generation. Nursing Forum, 51(3), 153-163. https://doi.org/10.1111/nuf.12133

Kirby, D. (2008). Advancing articulation: Models of college-university collaboration in Canadian higher education. College Quarterly, 11(4), 1-7.

Knowles, M. (1975). Self-directed learning: A guide for students and teachers. Prentice-Hall.

Ladouceur, M., Rideout, E., Black, M., Crooks, D., O'Mara, L., \& Schmuck, M. (2004). Development of an instrument to assess individual student performance in small group tutorials. Journal of Nursing Education, 43(10), 447-455.

Liu, M., \& Hu, Q. (2014). A proposed approach to informed consent for biobanks in China. Bioethics, 28(4), 181-186. https://doi.org/10.1111/j.-8519.2012.01985.x

Lunyk-Child, O. I., Crooks, D., Ellis, P. J., Ofosu, C., O'Mara, L., \& Rideout, E. (2001). Selfdirected learning: Faculty and student perceptions. Journal of Nursing Education, 40(3), $116-123$.

Majumdar, B. (1999). Empowerment through self-directed learning. The Canadian Nurse, 95(6), 37-40.

Majumdar, B., Roberts, J., Knechtel, R., Noesgaard, C., Campbell, K., \& Tkachuk, S. (1998). Comparison of self- and faculty-directed learning of psychomotor skills. Advances in Health Sciences Education, 3(1), 15-28. https://doi.org/10.1023/A:1009788629454

Mansell, D. J. (2004). Forging the future: A history of nursing in Canada. Thomas Press.

Mathisen, J., \& Bastoe, L. H. (2008). An unending challenge: how official decisions have influenced the teaching of nursing in Norway. International Nursing Review, 55(4), 387392.

Matthew-Maich, N., Martin, L., Hammond, C., Palma, A., Pavkovic, M., Sherement, D., \& Roche, C. (2016). Nursing students' perceptions of effective problem-based learning tutors. Nursing Standard, 31(12), 48-59. https://doi.org/10.7748/ns.2016.e10318

McPherson, K. (1996). Bedside matters: The transformation of Canadian nursing, 1900-1990. Oxford, University Press

Morton, P. G. (2017). Nursing education research: An editor's view. Journal of Professional Nursing, 33(5), 311-312. https://doi.org/10.1016/j.profnurs.2017.08.002

Muff, J. (Ed.). (1982). Socialization, sexism, and stereotyping: Women's issues in nursing. C.V. Mosby Company.

Mujica, I., \& Pierazzo, J. (2012). Re-shaping student engagement from small to large group while maintaining the essence of problem-based learning methodology [Summary paper]. Conference Proceedings of 3rd International PBL Symposium, Singapore. Centre for Educational Development, Republic Polytechnic.

Nelson, S., \& Gordon, S. (2004). The rhetoric of rupture: Nursing as a practice with a history? Nursing Outlook, 52(5), 255-261. https://doi.org/10.1016/j.outlook.2004.08.001

Neufeld, V. R., \& Barrows, H. S. (1974). The "McMaster philosophy": An approach to medical education. Journal of Medical Education, 49, 1040-1050. 
Oral History Association. (2018). Principles and best practices. https://www.oralhistory.org/principles-and-best-practices-revised-2018/

Pringle, D., Green, L., \& Johnson, S. (2004). Historical education in Canada: Historical review and current capacity. Nursing Sector Study Corporation.

Ramis, M., Chang, A., \& Nissen, L. (2018). Undergraduates intention to use evidence-based practice after graduation: A systematic review of predictive modeling studies. Worldviews on Evidence-Based Nursing, 15(2), 140-148.

Rideout, E. (Ed.). (2001). Transforming education through problem-based learning. Jones and Bartlett Publishers.

Rideout, E., \& Carpio, B. (2001). The problem-based learning model of nursing education. In E. Rideout (Ed.), Transforming education through problem-based learning. Jones and Bartlett Publishers.

Rideout, E., England-Oxford, V., Brown, B., Fothergill-Bourbonnais, F., Ingram, C., Benson, G., Ross, M., \& Coates, A. (2002). A comparison of problem-based and conventional curricula in nursing education. Advanced Health Sciences Theory Practice, 7(1), 3-17.

Rocco, T. S., Spangler, S., \& Boggs, D. L. (1998). Methodological considerations for comparing literary, historical, and living adults as data sources. Educational Gerontology, 24, 567583.

Rolfe, G., \& Gardner, L. (2006). Towards a geology of evidence-based practice: A discussion paper. International Journal of Nursing Studies, 43, 903-913. https://doi.org/10.1016/j.ijnurstu.2005.10.010

Ross-Kerr, J. C. (2003). Nursing in Canada from 1760 to the present: The transition to modern nursing. In J. C. Ross-Kerr \& M. J. Wood (Eds.), Canadian nursing: Issues and perspectives (4th ed., pp. 14-28). Elsevier Science Canada.

Sackett, D. (2015). Why did I become a clinician-trialist? Journal of the Royal Society of Medicine, 108, 325-330. https://doi.org/10.1177/0141076815596690

Scanlon, J. (1993). Challenging the imbalances of power in feminist oral history: Developing a take-and-give methodology. Women's Studies International Forum, 16(6), 639-645. https://doi.org/10.1016/S0277-5395(08)80008-8

Servant, V. F. C. (2016). Revolutions and reiterations: An intellectual history of problem-based learning [Doctoral dissertation, Erasmus University Rotterdam, the Netherlands]. RePub. https://repub.eur.nl/pub/94113

Simpson, E., \& Courtney, M. (2002). Critical thinking in nursing education: Literature review. International Journal of Nursing Practice (Wiley-Blackwell), 8(2), 89-98. https://doi/10.1046/j.1440-172x.2002.00340.x

Thorne, S. (2019). Graduate education. In C. McDonald \& M. McIntyre (Eds.), Realities of Canadian nursing: Professional, practice and power issues. (5th ed., pp. 183-200). Wolters Kluwer.

Toman, C., \& Thifault, M. C. (2012). Historical thinking and the shaping of nursing identity. Nursing History Review, 20, 184-204. https://doi.org/10.1891/1062-8061.20.184 
University of Alberta. (2020). Faculty of nursing. History. https://www.ualberta.ca/nursing/about/history.html

Von Schilling, K. (1973). The nature of the educational experience for nursing. Canadian Journal of Nursing Research, 5(3), 18-24.

Von Schilling, K. (1982). An educational process for effective teamwork. Nurse Education Today, 2(3), 5-7.

Walker, K., \& Holmes, C. (2008). The "order of things": tracing a history of the present through a re-reading of the past in nursing education. Contemporary Nurse: A Journal for the Australian Nursing Profession, 30(2), 106-118. https://doi/10.5172/conu.673.30.2.106 